CATALAN REVIEW

Catalan Review

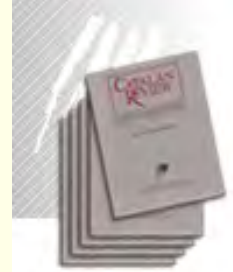

You are accessing the Digital Archive of the Catalan Review Journal.

By accessing and/or using this Digital Archive, you accept and agree to abide by the Terms and Conditions of Use available at http://www.nacs-

catalanstudies.org/catalan review.html

Catalan Review is the premier international scholarly journal devoted to all aspects of Catalan culture. By Catalan culture is understood all manifestations of intellectual and artistic life produced in the Catalan language or in the geographical areas where Catalan is spoken. Catalan Review has been in publication since 1986.
NORTH

AMERICAN

CATALAN

SOCIETY
Esteu accedint a l'Arxiu Digital del Catalan Review

A l' accedir i / o utilitzar aquest Arxiu Digital, vostè accepta i es compromet a complir els termes i condicions d'ús disponibles a http://www.nacs-

catalanstudies.org/catalan review.html

Catalan Review és la primera revista internacional dedicada a tots els aspectes de la cultura catalana. Per la cultura catalana s'entén totes les manifestacions de la vida intel lectual i artística produïda en llengua catalana o en les zones geogràfiques on es parla català. Catalan Review es publica des de 1986.

\title{
Language Management and Language Behavior Change: Policies and Social Persistence Albert Bastardas
}

Catalan Review, Vol. IX, number 2, (1995), p. 15-38 


\section{LANGUAGE MANAGEMENT AND LANGUAGE BEHAVIOR CHANGE: POLICIES AND SOCIAL PERSISTENCE}

\section{ALBERT BASTARDAS}

Notbing is as provocative for theory as practical problems and efforts. Joshua A. FISHMAN

\section{LANGUAGE MANAGEMENT AS A PROCESS}

\section{The socio-political evolution of western societies, that have come to} provide a model imitated by other non-western countries, has led, especially over the last two centuries, to an enormous increase in the functions and power of the state in the everyday life of the community. Language is one of the areas in which the state's influence has grown most quickly. Over and above the self-organizing and polycentric secular social dynamic used to solve problems of everyday linguistic communication, political authority has become, in many countries, the chief organizer of public language communication. In contemporary societies, then, the final choice of linguistic code or codes for institutionalized public life lies in the hands of political bodies. As a result, in general terms the language that the population must know is also decided by political bodies through universal and obligatory education. Political power will also decree-directly, or by delegating the task to academic institutions or linguistic authorities- the form of the code or codes to be used.

Nevertheless, the actions of political bodies take place within a complex sociocultural medium; this medium determines these actions, and in addition is regularly modified by them. It is highly likely that in order to reach a better understanding of sociolinguistic phenomena it will also be necessary to focus attention on society as a global and interrelated whole, of which political power is just one part, albeit a particularly influential one. For example, cases of linguistic normalization in present day Spain can be much better understood if we view them globally and dynamically whilst, at the same time, incorporating a vision of the cause and effect of current policies. Language management studies should take into account those actions which stem from political decisions as well as those brought about by 
organized social movements which herald a change in linguistic behavior and ideas. This would enable us to study, in an integrated way, the relations between political power and social movements; this in turn would lead to a greater understanding of the global processes of linguistic normalization. These processes are often initiated and promoted by the active militancy of specific social groups and not by the political power.

Political bodies can be very influential in determining global linguistic behavior, and so we should not underestimate the importance of the study and understanding of language policy -the set of measures taken by public bodies with the intention of intervening in society's linguistic communications-and its sociocultural effects. As a rule, one of the fundamental objectives of these interventions is to organise linguistic activity -even if it is only public linguistic activity -by assigning functions to one or more linguistic varieties. This assignation of functions has repercussions on the linguistic level; it strengthens or impoverishes the expressive capacity of different language varieties, according to the use they are accorded in public life. In a process of language planning, for example, reaching a certain level of standardization involves introducing measures that implant the language and reinforce its official status through governmental or legislative decisions. These measures aim to make the particular language variety the language of habitual use in administration, education and other official or paraofficial activities and institutions and in public life in general. If there is linguistic conflict the government can, if necessary, take action against the language variety which it does not want to be used in public life, prohibiting and penalizing its use in official spheres. This process may cause the particular subordinate language variety to be substituted. On the other hand, in a situation of linguistic plurality, if the state bases its policies on egalitarian principles, these policies will tend to assign language functions on the basis of territorial or even personal criteria and will also tend to offer protection to minority languages. The assigning of functions based on territory, as in the case of Switzerland, favors stability and the non-conflictive continuity of the various languages existing within the same state, so that they establish different, but juxtaposed, ecosystems (Bastardas \& Boix, 1994). This type of organisation, however, is more difficult to implant where there is a mixture of populations within the same territory-as is often the case in Spain-and in this situation functions may be assigned on the basis of personal criteria, either exclusively so, or in combination with territorial criteria. The ideological orientation of the political body has, then, a huge influence on the types of measure taken and on 
the overall evolution of the sociolinguistic situation. This evolution obviously bears a very close relationship with the language behavior norms and mental representations of the society in question.

Language policy is not, then, a static, given form, but a concept that reacts with and is shaped by other elements inside the sociocultural ecosystem. This ecosystem also includes all the other factors that control daily language behavior, factors that may (or may not) change in the direction that official language management desires. In this respect, then, there is an overriding necessity to ascertain as much as possible about the social dynamic of behavioral change and, correlatively, about the persistence of certain habits. No amount of descriptive data -as Kurt Lewin said-will solve the problem of which techniques to use to bring about the desired changes ${ }^{1}$ (1978:163). Imaginative theories and a conceptual knowledge of reality therefore become vital to the success of sociolinguistic planning, Continued observation, dispassionate and objective analysis of situations, research into causes and dynamics, the eyaluation of real experiences and the reformulation of strategies and concepts are fundamental, unavoidable tasks in which both theory and understanding are vital components (see Bastardas, 1994). The study and understanding of actions and ideologies in the political sphere regarding institutionalized and individualized language uses and its codes, and their interrelations in the sociocultural medium should be studied together and should figure among the fundamental objectives of sociolinguistics as a highly interdisciplinary scientific field.

\section{APPROACHING SOCIOLINGUISTIC COMPLEXITY:}

THE ECO-SOCIO-DYNAMIC PERSPECTIVE

This century has seen some remarkable changes in scientific thoughtan astonishing range of technical achievements and, perhaps even more importantly, a rethinking of fundamental aspects of the basic postulates of science. Successive transformations, particularly in physics, have raised serious doubts about the philosophical foundations of scientific thought and about our models of reality. In spite of the flow of information in society today it appears that the conceptual revolutions of the first half of this century have not had in other disciplines the impact they have had in physics. For example, in socio-cultural science today there is a sense of pride that the calming empiricism which

\footnotetext{
${ }^{1}$ All quotations from non-English books are my own free translation.
} 
physics adopted towards the end of the last century has finally been incorporated, whereas in contemporary physics the mind of the observer is now assumed to be a vital part of current theories. Likewise, whilst the models used in other sciences still tend to be analytical and reductionist (looking for truth in the final, irreducible components of their particular reality) theoretical physics now also uses a bolistic approach and has embarked on an exploration of the models and images adopted by oriental cultures. The universe is seen as an ever-changing spider's web of interrelated events. None of the properties of any part of the web is fundamental; each follows the example of the properties of the other parts, and the overall consistency of their mutual interrelations determines the structure of the whole (Capra, 1984:324).

Taking the reflections of theoretical physics as a starting point, it seems clear that the application of a systemic and dynamic perspective to phenomena of language management is not only advisable, but vital to a thorough understanding of the field, its causes, and its social consequences and effects. Viewing socio-politico-linguistic events inside an ecological-type framework (Haugen, 1972; Mackey, 1994; Bastardas, 1993. 1996) which takes account of their causes and micro and macro dynamics and which allows us to understand their evolution and transformation is, today, an unavoidable necessity in any branch of socio-cultural science.

Ecology, for example, gives us the idea of ecosystems, though on transferring this concept to sociocultural sciences we need to emphasize cultural rather than physical aspects. The idea of the ecosystem - a level of reference formed by discontinuous individuals, together with the materials that are the result of their activity (...) and their matrix or physical surroundings of which they form a part and where they carry out their activities (Margalef, 1991)- provides an interesting point of departure when beginning to sketch the complicated landscape in which language management and language behavior change are located. Likewise, theories such as that of interaction between species provide extremely interesting formulations in the analysis of linguistic contacts. Ecology therefore focuses our attention on the importance of the medium in which phenomena occur, an element of crucial importance in understanding the structure and evolution of language processes.

Ecologists affirm that when there is interaction between two groups or species the relation is not binary but ternary, i.e., it consists of three elements, the third being the environment in which the interaction takes place. This concept can be usefully transferred to the field of sociolinguistics. If we postulate that the sociocultural world 
consists largely of institutionalized linguistic communications (Corbeil, I980), i.e. communications that exist because of and in relation to the institutions or organizations (official and non-official) of which society is composed -government, school, media, advertising, etc.- these communications constitute a type of sociolinguistic space which escapes the direct control of the individual but has an influence on the bulk of society as a whole. This type of linguistic emission contrasts with individualized communication - private and informal language actions between neighbors, workmates, friends, etc., in everyday life. It is highly likely that, in the linguistic ecosystem, institutionalized communications will exercise an important, dynamic influence on the linguistic behavior of individuals, and may on occasion lead to dialectal homogenization or language shift. Understanding the interrelation between these two levels of communication would be an enormously useful step on the way to developing a global theory of language behavior and language management.

\section{PERSISTENCE AND CHANGE IN SOCIOLINGUISTIC MANAGEMENT}

Human societies contain elements which favor persistence in cultural and linguistic behavior - especially intra-generationally - and elements which favor change - more likely to evolve inter-generationally. Which elements help us to understand the dynamics of processes and to carry out sociolinguistic planning in order to ensure, for example, maximum use of a language in recession both in institutionalized and individualized communications? At least three important, complementary aspects should be considered here: persistence, resistance and change itself. We shall look at the first of these aspects now. Human behavior shows a tendency towards functional persistence. The subconscious is responsible for a large part of human behavior, and so once a certain behavior has shown its efficiency and functionality in everyday life it becomes routine and occurs without the subject being aware of it, until a new behavior becomes the norm. Many norms in language behavior have this characteristic, which may explain the sociological observation that many types of behavior persist even though the conditions which led to such behavior disappear. The concept which perhaps most adequately explains this phenomenon is that of habitus, which Pierre Bourdieu defines as systems of durable and transposable dispositions, structured structures which are predisposed to function as structuring structures, that is to say as generative and organizing principles of practices and representations which might objectively be adapted to their goal without supposing a conscious vision 
of the ends or conscious manipulation of the necessary operations attending it, objectively regulated and regular without being at all the product of obedience to the rules, and orchestrated collectively without being the product of the organizing action of the leader of an orchestra (1980:88). Accordingly, not only the problem of persistence affects pure action, but the whole cognitive plan is organized in such a way as to make change difficult and to maintain -also often unconsciouslyrepresentations of reality interiorised at an earlier stage. Persistence is then a factor of great importance which planners or politicians must overcome if they are to achieve their objectives. Alerting individuals to the situation, heightening their awareness of it, and ensuring that they do not reject a vision which differs from the one that they have come to perceive as "normality" may well be no simple task, at least until certain structural changes have occurred in their surroundings.

The habitus installed in people's minds needs to be shaken off if they are to reorganize their systems of interpretations and formulate new visions of reality which favor changes in specific behavior. In all probability the modification of ideas and of social behavior on a mass scale will be more difficult if individuals do not perceive that the new situation represents a step forward, be it for instrumental or utilitarian reasons, or for reasons of identification. It will be even more difficult if the changes are seen as threatening or inappropriate. We must not discount, then, the possibility that the attention that individuals pay to the changes may well cause them to resist them rather than to accept them. Whether for ideological or practical reasons, many individuals may decide not to accept the new situation; indeed, they may actively oppose it. In fact, given that the advantages or disadvantages of changes in behavior will not be tangible until the new norms are put into practice, the immediate problem will be the value hierarchy and the ideological framework within which the changes are evaluated. For this reason, the level of conflict between supporters and opponents of change can vary according to the extent to which the modifications shape the new situation, and according to the extent to which they tie in with expectations of it.

Even if we succeed in overcoming initial ideological representations which make acceptance of the changes difficult there will still be elements of resistance due to the inconvenience involved in implementing them. This type of resistance will come above all from individuals who do not personally support the change. An example might be that of linguistic competence. In this case, a person's linguistic knowledge may greatly influence his/her attitude towards change. A person who is capable of using - or learning to use- a certain instrument of communication without difficulty will tend to offer less resistance 
than a person who sees the task as time-consuming and costly. One would expect, then, to find a certain degree of resistance amongst people who, at the beginning of the process, had to acquire the necessary knowledge to be able to use the new standard variety in institutionalized communications.

These and other resistance-generating factors should alert the planner to the need for in-depth study of a particular area of intervention before attempting to influence it. If our aim is to design an optimal type of intervention, it is vital that sociolinguistic planning should understand ideological representations, the norms of linguistic use, competence and, in general, the contexts of the individuals or organizations whom any change will affect.

\section{LANGUAGE MANAGEMENT IN SPAIN: \\ LANGUAGE NORMALIZATION PROCESSES}

IN A STATE WITH A HISTORY OF OFFICIAL MONOLINGUALISM

Spain is one of the most linguistically complex states in the European Union. Four languages in particular stand out: Basque, Galician, Catalan and Castilian - the last of which is frequently referred to as "Spanish." The populations of the areas in which the three non-Castilian languages are also official languages represent over a third of Spain's total population. The sociolinguistic situations of the three languages differ widely, however, and there are even differences within each area. ${ }^{2}$

The Basque, Galician and Catalan-speaking populations share certain common characteristics that define the current situation in non-Castilian speaking parts of Spain (Bastardas \& Boix, 1994):

1. In all three cases the greater part of speakers of the three languages occupy compact, self-contained territories; they are not scattered around Spain.

2. The languages of the three communities do not have the same legal status as Castilian in the state's central governing bodies. Within their linguistic limits and within the "autonomous communities" (communities with regional governments), Basque, Galician and Catalan share equal status with Castilian as official languages. Castilian is, nevertheless, the only official state language as such, which means

${ }^{2}$ More detailed informations on multilingualism in Spain can be found in BastardasBoada (1986 and 1989), Siguan (1991), Bastardas \& Boix (1994), and Etxebarria (1995). 
that Spain presents itself officially as a monolingual state. This legal regulation is the extension of a historic process: the expansion of Castilian, an expansion which, until a few years ago, involved an asymmetrical process of unilateral "bilingualisation" within non-Castilian speaking populations. Castilian thus become indispensable, and the other languages lost ground; all of them felt the impact of the process of language shift, and some became almost unnecessary within their own territories.

The policy of Spanish governments since 1978 - the year of the new Constitution - has not essentially altered either the legal framework or the monolinguistic inertia of the central government in most of the areas inside its jurisdiction. As a result, recognition abroad of the Basque, Galician and Catalan languages is almost nil. Catalan citizens and organizations cannot communicate with the central government in Catalan, even in writing, in spite of the fact that Catalan is the second most widely spoken language in Spain; only rarely do they receive communications from the central government in Catalan. Comparison with a country such as Switzerland, for example, whose egalitarian principles allow the French minority to be Swiss without renouncing their own language, spotlights the ground still to be covered.

Nonetheless, within this limited framework, the new autonomous governments of the Basque, Galician and Catalan-speaking areas have, with varying degrees of commitment, set in motion processes of linguistic normalization aimed at (re)instating their own standard language in institutionalized communications. In doing so they aim to halt the processes of linguistic extinction and to construct new sociolinguistic ecosystems which will permit the recovery and habitual use of their own languages and which will guarantee their future stability and normality. These normalization processes resemble each other in so far as they encourage the customary processes of standardization - given that the political conditions that prevailed in the past made the normal existence of a standard variety impossible but differ, obviously, due to the complexity of their respective situations. This complexity resides in the fact that in these territories many people do not speak the local language and use only Castilian, because of intergenerational language shift, or because they are immigrants from other language areas of Spain. For this reason, points of departure in the different areas have tended to vary. For example, in the Basque country - even though the population in the main supports self-government and is proud of its culture - individuals who habitually use an autochthonous vernacular language variety are in the minority in the population as a whole. In this case, then, the process is not simply one of typical standardization but one of recovering the 
autochthonous language variety and using it for communicative functions in all areas, official, public, or private,

In the case of Galicia, the situation is different again. Of all the nonCastilian linguistic communities, Galicia has the highest proportion of residents who know the indigenous vernacular varieties, and is thus in theory the community with the most favourable preconditions. Nonetheless, the commonly accepted ideas of the value of local linguistic forms work against the normalization of Galician. As often happens in a situation characterized by long term political and economic subordination, the speakers of vernaculars come to see their own language negatively, devaluing it symbolically and investing standard Castilian - used in all official and non-official public functions - with great prestige. Given that a majority in Galicia do not appear to share the political ideal of linguistic emancipation, linguistic policy does little to encourage the rapid incorporation of Galician in institutionalized communications. This situation has obvious repercussions for the overall advancement of the normalization process. The case of Galicia also provides an example of the problem of reaching social consensus on the form of the standard variety. Languages with a longer history of standardization, such as Castilian or French, have overcome this problem; in contrast, in Galicia, there exists the dilemma of whether to plan the language so that it is closer to Portuguese - a language which is, in fact, descended from Galician, and which would integrate the community more in the Luso-Brazilian sphere - or whether to move closer to Castilian, a language with which Galician has co-existed for long periods of its history. The society is divided over the issue. Once again, individual ideologies and interpretations of a particular situation, and the relations between these individuals and other groups, are factors of enormous importance in explaining the strategic options chosen for language policy and language planning.

In the normalization processes in the Catalan-speaking area there are also internal differences. Whilst in Catalonia the great majority of the indigenous population habitually speak their own vernacular, in the Valencia region a high number of the indigenous population, especially in the cities, now use a more or less standard Castilian -though with local characteristics- even in informal communication. They use Castilian when talking to their children, a fact which has interrupted the normal intergenerational transmission of their own vernacular. A similar situation has arisen recently in the Balearic Islands, although perhaps with less intensity than in the case of Valencia. The linguistic policies adopted by the various autonomous governments also differ. In Catalonia progress has been made in introducing a standardized 
variety of Catalan as the linguistic vehicle of a unified education system; it is the language normally used in autonomous and local administration, and on two television channels. In the Valencia region, in contrast, the autonomous government has opted for a policy of providing two separate lines of education, so that people can choose to have their children educated in Castilian or in Catalan-legally called Valencian. The autonomous television channel does not use Valencian exclusively or even predominantly, a fact which means that knowledge of the autochthonous language is not spread as efficiently as in Catalonia. Another factor in the Valencia region has been the lack of consensus on the adoption of the new standard variety, rejected by certain groups that consider it excessively "Catalonia-oriented." These same groups have tried to promote the adoption of a standard variety which differs slightly from that used in the rest of the Catalan linguistic area. The situation is also different in the Balearic Islands because the education system there comes under the direct control of the central education authority, a body that is in general hostile to the use of the local language in education. In all three cases there is also the problem of the presence of large numbers of inhabitants from other parts of Spain, generally Castilian speakers, a phenomenon which has made it difficult to adopt political measures which would work towards the recovery of the local language. The case of Valencia is further aggravated by the fact that the interior fringes of its territory have historically been Castilian-speaking.

These cases of language management in Spain are still taking form and emphasize clearly the need for dynamic, integrated theorizing which takes into account changes in the situation and the interrelation of factors which bear on that situation. In this case, language management must especially bear in mind the relation between language policy and its overall effect on society; it must be able to explain why certain goals and cases of language management are successful whilst others, with similar regulations, fail (take, for example, the case of Ireland). Understanding these phenomena involves, then, the need to look not only at official linguistic regulations but at the other aspect - those elements in society which favor the persistence of established behavior and their relation to sociocultural and political change. 


\section{PLANNED LANGUAGE BEHAVIOR CHANGE}

AND SOCIAL PERSISTENCE IN HISTORICALLY SUBORDINATED GROUPS: THE EXAMPLE OF CATALAN.

As we stated above, the present linguistic normalization process undertaken in Catalonia at the end of the dictatorship in Spain (see Bastardas 1986, 1987 and 1989) has produced an important advance for Catalan in the field of institutionalized communications - such as the educational system, the local and autonomous public administration, radio and television, etc. However, changes in the field of oral one-toone inter-personal communications have been far less marked, especially in the interactions of the $\mathrm{Lr}$ Catalan indigenous population with $\mathrm{LI}_{\mathrm{I}}$ Castilian-speaking immigrants. As many people from other regions tend to use Castilian rather than Catalan in their inter-group communications, most native Catalans linguistically adapt to the immigrants and use Castilian in order to follow the speechconvergence principle in daily conversations.

In fact, the most usual behavior of the indigenous population in their social framework seems to be to speak Castilian in general to any person perceived and considered as a non-Catalan speaker (Boix, 1989, 1990, 1993; Tuson, 1985, 1990; Woolard, 1983,1992), with the exception of a conscious, militant minority who maintain the use of Catalan in all situations. Thus the norm of Catalans using Castilian -or Spanish- is applied to unknown individuals who are addressed in Catalan but answer in Castilian, and also to people who are now able to speak Catalan but with whom initial contacts were conducted in Castilian and with whom the use of Castilian is thus established. The norm is also followed - especially in Barcelona and its Metropolitan area - to speak to individuals with professional or social roles perceived as usually belonging to people who do not use Catalan - for example, waiters, taxi drivers, policemen - and also when speaking to children of immigrant origin who are assigned the linguistic categorization of their parents, or even strangers one meets in the street. The indigenous population tends initially to address these individuals in Castilian rather than in Catalan. In addition, members of the Catalan-speaking indigenous group may themselves conduct conversations in Castilian although these conversations are sometimes (but not always) re-directed to Catalan in the event that one or both speakers stop considering the other individual as a non-Catalan speaker (owing to his/her accent, etc.).

This situation is evidently the result of the historical contexts in which these successive encounters between autochthonous and allochthonous individuals have taken place. These historical contexts are generally characterized by the absence of Catalan in the 
institutionalized areas, and the predominance of Castilian especially in the schooling system, the mass media, and the administration. This fact gave rise to a general asymmetric bilingualization of the Catalan inhabitants, favoring Castilian (in oral and written forms) and downgrading Catalan (used only orally and informally, due to the almost total absence of any formal public use under the dictatorship). This situation maintained monolingualization among many immigrant people who had Castilian as their first language. Generally speaking, in all these historical contexts, intergenerational population substitution gradually favored the progress of bilingualization amongst inhabitants of Catalan origin, increasing their use of Castilian; it did not increase in the same degree the use of Catalan among immigrants, especially in the large cities. The persistence of Spanish monolingualism among most of the new generation of immigrants favored the use of Castilian by young Catalans, who spoke the predominant language with ever greater fluency and ever greater frequency. As a result, there were far more indigenous individuals who spoke Castilian regularly to immigrants than immigrants who spoke Catalan to native Catalans. As time went by, the norm of using Castilian to address all individuals categorized as non-Catalan speakers became a totally interiorized, automatic behavior, seen as completely natural by most of the entire population. The initial posture, adopted to make communication possible with recently arrived immigrants who spoke a different language, gradually transformed - despite the gradual rise in competence (in receptive competence, at least) of a substantial number of immigrants - into a widespread social custom, sanctioned by habit, with all the consequences that this linguistic use had for the changing of such behavior patterns.

With the advent of democracy and the restoration of a certain amount of political autonomy at the end of the seventies, Catalan and Castilian were declared co-official languages in Catalonia. As we said, the Catalan Government took steps to encourage linguistic change in the educational system and the new autonomous administration, supporting the generalized use of Catalan in public communication. It also created mass media services in Catalan, and other measures were taken in local administration and sectors involving cultural and economic activities. The bodies in charge of the new linguistic policy in Catalonia also tried to make the population aware of the problem of the predominance of interpersonal language behavior that favored the use of Castilian. The Catalan Government embarked on a campaign advocating what were called bilingual conversations (in which each person speaks in his or her first language) and encouraging the use of Catalan in all situations and social domains. These campaigns included 
messages of the type: "Catalan depends on you" or "in Catalan you show respect for yourself and others." Although the precise impact of these campaigns and the substantial political changes on the intergroup language behavior of the indigenous population cannot be reliably assessed, what we can say is that change is a slow process, and by no means general. Few native Catalans conduct bilingual conversations; the majority automatically adapt to the other speaker in one-to-one interactions, even when, as is now commonly the case, the other speaker has a good understanding of Catalan. How can we account for the persistence of the use of Castilian with non-Catalans who understand Catalan? Why is the behavior change so slow? These issues coincide with those described by Bourhis (1984) with reference to the French/English case in Quebec. Bourhis also perceived that Frenchspeaking individuals followed the norm of adapting linguistically to English-speakers, in spite of the efforts at governmental level to raise the status of French in Quebec and to increase its use.

Although the situations in Quebec and Catalonia are different in many important aspects, both cases are in all probability an example of the general social perpetuation of a wide range of routines, habits and functions in spite of political pressure and legal measures taken by official authorities. In this context, we will now explore some factors which may explain this sociolinguistic evolution.

\section{SUBCONSCIOUSNESS}

One factor that may go a long way towards explaining the phenomenon of the persistence of behaviors established within settings subsequently modified by political power is, probably, the fact that much social behavior -especially linguistic behavior-is subconscious (Bourdieu, 1982; Gumperz, 1985). Once a social norm for a specific area has been created, the norm becomes routine; it becomes subconscious. It will receive no further attention unless some kind of crisis emerges. Habit substitutes conscious thought (Nisbet, 1982); the individual will only become aware of the deficient nature of the scope of bis/ber knowledge when a new experience does not adapt to what had been considered as the presupposed valid reference scheme up to that moment (Schutz \& Luckmann, 1977:29). In all likelihood, few LI Catalan natives will have experienced a crisis that severely questions their usual way of addressing non-Catalan speakers. For the most part, the current organization of interpersonal linguistic use between natives and immigrants works efficiently. Other factors of a symbolical and ideological nature which could raise doubts about the present norm do 
not seem to be sufficiently strong for the majority of the population to feel the need to modify their behavior -at present at least.

Thus, generally speaking, attention is paid more to the content than to the code, despite the ideological value afforded to the latter. This situation may well be typical: a population that persists in behaviors which may have negative consequences for the autochtonous language in the future, but which work perfectly well in practice. The awareness campaigns carried out to date have not been powerful enough to draw the attention of Catalan-speakers to the need to change a behavior which is deeply ingrained but, in the final analysis, negative.

\section{CONSCIOUS ASSESSMENT}

Another part of the population, generally better informed and more given to reflecting on and assessing personal behaviors, empathizes with the government messages, and take the issue seriously. Nevertheless, these people may argue against this change in behavior towards individuals who understand but do not speak Catalan on the ground that it could be interpreted as a lack of respect and good manners. The time-honored practice of speaking Castilian in this situation is one of the reasons why they would not tolerate or even conceive of speaking Catalan to non-Catalan-speakers. They defend their present linguistic behavior towards the non-bilingualized, non-Catalan population at the level of oral expression. Their habitus automatically excludes any behaviors which may be seen as anomalous (Bourdieu, 1980). These people either ignore or argue away the anomaly which their behavior represents for the indigenous linguistic community, and disregard the possible results of their behavior in the future.

There is yet another group within the indigenous population that conceives of another possible, normal situation in which it is the individuals of immigrant origin who adapt linguistically, and not the natives. The attitude of this group is probably a result of a representation of reality which differs from that of the former group, together with a set of ideological predispositions which tend to see the present reality in a different way. These people consider the idea of the bilingual conversation to be reasonable. The most committed among them try to put the principle into practice, but find it hard to do so in real social life. Relationships with totally unknown individuals, and in institutionalized, formal situations rather than individualized ones - as in situations in which the indigenous individual is in a position of "nonsubordination" or "non-absolute necessity" (a customer in a shop, a customer asking for some kind of service, etc.) present little problem. 
Difficulties arise, though, in situations in which the non-Catalan speaking interlocutors have a higher social status - a higher professional category, etc. - or if the Catalan-speaker is in the minority, or in other situations in which the use of Catalan could be interpreted as entailing certain negative consequences.

A part of this population will probably not insist on a bilingual conversation when speaking with non-Catalan individuals in informal and friendly situations, in which mutual empathy is highly valued. It will also be difficult to introduce this norm with individuals with whom the Catalan-speaker has so far spoken in Castilian. The consolidated habit of speaking Castilian to a specific person will become a very powerful constraint on the change of linguistic behavior. In all these conscious assessments of linguistic behavior change, the social significance of changing the norm plays a fundamental role. The fact that behavior is subconscious does not mean that habitual actions lose their significance regarding the individual (Berger \& Luckmann, 1983), because, as G.H. Mead stated, awareness or consciousness is not necessary to the presence of meaning in the process of social experience (1934:77). The breaching of generally accepted and followed social expectations is not, then, a neutral, connotation-free fact, but an issue that attracts the attention of the interlocutor (obviously enough) and of the others present during the communication: they will all probably notice the change and will assign meaning to it. The awareness of this effect and of the repercussions of the assessments of the other individuals may well be a decisive factor in the maintenance and persistence of many social behaviors, because the individual in question values - and, to a considerable degree, depends on - the esteem and positive consideration of the people with whom he/she is regularly in contact (Berger, 1963; Davis, 1984; Milroy, 1987). (This fact probably also accounts for the speech-convergence observations described by Giles and colleagues). In the case of Catalan as well, natives are probably aware that their new intergroup behavior could be interpreted negatively; they may well be intimidated by the history of the relationship of the groups in contact, and may feel a hidden symbolical violence (Bourdieu, 1982).

Moreover, among the individuals who have decided to adopt the new norm it may frequently be the case that, in an interaction in which they have decided to use Catalan, they end up speaking Castilian because of behavior automatization - i.e., they respond in Castilian upon hearing a message in this code. This automatization may lead Catalan-speakers to change language whenever they drop their guard, especially in the initial period when the new behavior is as yet unassimilated. This is frequently observed in debate programs on 
television in which the group consists of individuals from both linguistic groups: even ministers of the Catalan government switch to Castilian - in a program or channel which is identified as Catalan - to respond to an interlocutor speaking Castilian. This occurs especially when the debate becomes heated and the scope for conscious control of the linguistic behavior diminishes.

Consequently, the persistence of the old behavior, in spite of official language management programs at government level, seems to respond mainly either to the functional and subconscious nature of the current linguistic intergroup behavior or to the fear of negative assessment of this change by non-Catalan speakers.

\section{SOME PRINCIPLES AND INEERENCES FOR THE MANAGEMENT OF LANGUAGE BEHAVIOR CHANGE}

The analysis of persistence in spite of language management strategies shows that, as in other sociocultural matters, the situation that faces us is not one that is easily transformable but a complex situation in which results will take time. It requires an ecological macro and micro approach. Attracting the attention of the Catalan-origin population, providing them with good reasons for language behavior change and overcoming the automatic response problem are not easy tasks; the process may well take more than one generation. The present intergroup linguistic usage norms are rooted in everyday life, and, as we have seen, they are efficient. For this reason, continuity is far easier than change. A new micro approach to the change of code-switching behavior in intergroup relations as a part of a language management process should take the following points into account:

A) Any majority change regarding language behavior norms in oral interactions tends to be slow. A direct intervention on the part of the political institutions is unlikely, especially in instances in which common usage has fulfilled its communicative function. It is for this reason that Bourdieu can say that linguistic mores are not modified by decree, as those who advocate a well-intentioned policy of language defence often believe (1982:36). Social uses consecrate a series of specific norms maintained by the social interaction itself. This interaction tends to be founded on mutual expectations which are generally taken for granted and which may lead to some kind of social sanction if they are not obeyed and followed (Davis, 1984).

B) Linguistic behaviors tend to become routine and subconscious actions - the only exception being that of a generalized situation of 
conflict, which is not the case in Catalonia - in which individuals consciously concentrate more on the specific meanings to be transmitted rather than on the vehicle they use to transmit them.

C) Faced with the planned implementation of a change, the speaker will assess its reasons and effects, and will act accordingly. If the change is considered appropriate and legitimate and unlikely to have negative consequences, the speaker may decide to implement it. In order to do so it is necessary to overcome the initial difficulties posed by the existence of a firmly rooted behavior automatization (Bandura, 1982).

From the macro point of view, the planned management of language behavior should start from a global and interrelated view of the problem. The two coexisting groups should be seen together, as a unit of analysis. Due to the difficulties involved in changing the language behavior norm of Catalan-origin people, the project should be approached from the view of the ecosystem. In this context, the problem can be reformulated. For example, one can see now that the intergroup use of Catalan by indigenous people will only increase massively if the immigrant-origin individuals also speak Catalan or, to a lesser extent, when these people show a clear and positive acceptance of the change. In fact, the situation will in all probability change to the extent that the immigrant population speaks Catalan with those of native origin. If this is so, the generalized change of the behavior of Catalan speakers may depend on the behavior change among those of immigrant origin. The central issue, then, may not be how to change the behavior of Catalan speakers, but how to contribute towards the change amongst the immigrants. It is a question of how to create a situation in which all or most intergroup relationships are built up in Catalan and not in Castilian, as has been the case up to the present time. The problem, from this perspective, lies mainly in the fact that the immigrants do not speak Catalan and not in the fact that Catalan speakers address them in Spanish. Thus both groups simultaneously require a global focus which enables a comprehensive, dynamic understanding of the situation, bearing in mind the circular and retroactive - not linear - causality in human interaction (Elias, 1982). We should focus our efforts mainly on the new generations, and especially on those whose first language is Castilian.

Language management theory, then, has to bear in mind the psycho-sociological laws concerning the perpetuation of social norms and the dynamics of behavior change. Linguistic usage norms are, in a certain way, autonomous, and tend towards self-persistence, as they are strongly maintained by means of social control - the result itself of 
human interaction and also of the need for the esteem and approval of other people. The situations in which the possibility of change appears to be highest are those of inter-generational transition, in which new socialization processes are taking place. It is at this moment that linguistic competence is developed, behavior norms are formed and adopted, and identities are acquired (Berger \& Luckmann, 1983). Some innovations -even though they differ from adult behavior- can be adopted and extended, and even though some of them may disappear during the evolution of the generation itself, others will remain.

The changes in linguistic behavior seem, in general, to follow a dynamic similar to that of other spheres of human social behavior. The acceptance of change will probably depend on the assessment of its advantages and drawbacks according to the representation of each concrete social reality. Changes seen as legitimate, and justified in this definition of reality, will be implemented more rapidly, and will consequently extend from the original dynamic nuclei to the rest of society. Nevertheless, those changes which may generate social resistance may not gain generalized social acceptance, and may entail social sanctions and practical disadyantages in everyday life. They will encounter many more difficulties before they expand and root, to the extent that their social introduction on a mass level may eventually prove impossible. However, these changes which like linguistic changes involve complex motor abilities, will tend to be slow precisely because of the non-permanent predisposition of human beings towards the development of such complex abilities. Thus, in the case of linguistic events, the extent to which the necessary abilities are developed will be an important factor, and it may influence individual attitudes and the degree to which the changes take root. On the other hand, the degree to which such linguistic abilities develop often escapes the control of the individual involved, and depends on the structure of the contexts in which he/she participates.

The Catalan case is also representative with regard to the birth of the norm of language use in intergroup encounters. The norm will be the product of the conditions of the particular moment and of the past history of the different human groups in contact. The level of language competence developed up till then by the individuals involved, the representation of reality as a result of their previous experiences, and the power relationships existing between the groups will determine the choice and the evolution of the intergroup linguistic behavior. If headway is made towards a deep and stable social integration, this norm will probably have an impact on the direction of future linguistic changes in the new plural society. Changes in the norm initially adopted by a majority, and implanted further by daily routine usage, 
will not be easily achieved by language management intervention on the individuals themselves.

\section{CONCLUSION: \\ SOME POINTERS FOR THE CATALAN LANGUAGE NORMALIZATION PROCESS}

If change in the real linguistic behavior of a population is not easy to achieve, what can be done to facilitate it? What factors favor change? How do we overcome persistence and resistance? Kurt Lewin can also help us here: because a group's babit has lasted a long time does not necessarily mean that that habit is a rigid one, but simply that there bave been no changes in related conditions during that period (1978:164). This means that intervention for change should concentrate not directly on the babits of individuals but on their surroundings, on the ecosystem in which they live, the aim being to change the sociomental factors which determine their behavior, especially institutionalized communications. The specific objective of intervention then should be to achieve change in the cognitive representations of the people in control of organizations (politicians, company owners and directors, directors of associations, etc.). By acting effectively - slowly and flexibly, but with a clear idea of the objectives - political powers (or civil movements promoting sociolinguistic intervention) can achieve good results if they base their actions on legitimisation, cooperation and facilitation and not on direct coercion. It is highly probable that sociolinguistic intervention will be more effective if it acts on the communications of organizations and not on individual communications. Changing the opinion of certain leaders in the productive or commercial sectors, for example, may well be less difficult than attempting to change the specific behavior of individuals. If two people are used to speaking to each other in $Y$, for example, they are highly unlikely to change to communicating in X. Or again, if a person has interiorised the idea that his children should not speak in $\mathrm{X}$ but in $\mathrm{Y}$ our powers of persuasion must be great indeed if we are to persuade that individual to change, unless he/she is convinced ideologically or has seen sufficiently clear evidence of change in his/her environment of the importance and need for X. Thus, any intervention based solely or almost solely on an attempt to interfere directly with individual cognitive representations is liable to fail unless it is accompanied by real transformations in public communications (in administration, education, commercial activities, the media, etc.) which validate expectations regarding the new situation (see Hindley, 1990). 
All these problems are extremely difficult to solve in the case of already socialized adult individuals. Children, however, are in the process of socialization and are virtually without ingrained habitus; as they are biopsychologically open to their environment, they are much more amenable to sociocultural change. The careful structuring of contexts for the socialization of children can permit the development of linguistic competence in the chosen language and the establishment of new usage norms, as well as representations of reality which are nearer language management goals. It should be borne in mind, however, that the socialization process may take place in an ecosystem which is still dominated by adult society, the values and behavior of which may diverge from those desired by the socializing institutions. In any case, intergenerational change should be the main focus of the process (see Bastardas, 1985). If we have to choose which institutionalized communications to prioritize it is clear that the most vital and urgent intervention should be in the communications to which children are most exposed. As the most fundamental sphere in linguistic socialization still appears to be the family, studies of persuasive intervention in this area are required, even though, as we are dealing with individualized communications, success in this area is by no means guaranteed. On the other hand, the need for intervention in the linguistic inputs that children receive from social organizations is more pressing and more concrete. In the case, for example, of current linguistic normalization processes in Spain, the (re)introduction of the indigenous variety as the linguistic vehicle in education (even if it is not exclusive and the process is carried out as gradually as seems convenient) as well as in other areas related to or outside education (leisure centers, videos, special television programs, board games and computer games, comics and magazines, etc.) is absolutely vital. At the same time, there is a need to introduce schemes in other areas of human activity which aim to project an image of the normalization process as irreversible. Beginning, for example, with "fixed" communications (signs, printed matter, recordings, etc.) and moving on to oral communications which are more directly related to the public, etc., would be an example of a gradual strategy but one which, at the same time, would have maximum impact on the population's definitions of reality with the resulting potential influence on individual behavior. Identifying the optimal criteria for prioritisation - the degree of acceptance according to sectors, geo-social areas, age, socio-economic groups, etc. - and being able to see how they relate inside the ecosystem is a necessary task and one which cannot be transferred mimetically from one society to another (see Bastardas, 1991).

The complexity of human society - as the Catalan case shows - 
demands language management strategies based on an eco-dynamic and interdisciplinary perspective that integrates micro and macro social sciences approaches. Both locally and globally, we need to move towards the creation of explanatory models leading to a theory of language planning in which hypotheses will form a network of testable assumptions and a unified body of cumulative and objective knowledge open to future refinements (Cobarrubias, 1983:25).

\section{ALBERT BASTARDAS BOADA UNIVERSITAT DE BARCELONA}

\section{REFERENCES}

\section{BANDURA, Albert}

1982 Teoría del aprendizaje social. Madrid: Espasa-Calpe. (Spanish translation of Social Learning Theory, Prentice-Hall, 1976).

1986 Social Foundations of Thought and Action. Englewood Cliffs, N.J.: Prentice-Hall.

BASTARDAS-BOADA, Albert

1985 'L'assimilació lingüística dels immigrants: l'experiència internacional i el cas de Catalunya," Serra d'or 312 (sept.), pp. 6ri12.

1986 The Relation Between Linguistic Context, Behaviour, and Competence: The Second Generation of Castilian-Speaking Immigrants in Non-Metropolitan Catalonia. Quebec: CIRB, Univ. Laval.

1987 "L'aménagement linguistique en Catalogne au XXe siècle," in: Maurais, J. (ed.), Politique et aménagement linguistiques. Quebec/Paris: Conseil de la Langue Française / Le Robert, pp. I2I-I58.

1989 "Language-Use extension in linguistic normalization processes: General patterns and the Catalan experience," Catalan Review vol. III, n.I (July), pp. 59-84.

1991 Fer el futur. Sociolingüistica, planificació i normalització del català. Barcelona: Empúries.

1993 "Llengua catalana i futur: notes des d'una perspectiva ecosistèmica," Revista de llengua $i$ dret 19 (July), pp. 8I-93.

1994 "Sociolingüística aplicada i planificació lingüística," in Actes de la segona trobada de sociolingüistes catalans. Barcelona: Dpt. de Cultura, Generalitat de Catalunya, pp. 7- II. 
I995 "Política i planificació lingüístiques: perspectives i preguntes per a un camp interdisciplinari," Revista de llengua $i$ dret 24 (decem.), pp. 145-163.

1996 Ecologia de les llengües. Medi, contactes $i$ dinàmica sociolingüística. Barcelona: Eds. Proa.

BASTARDAS, Albert, \& Emili BoIx (dirs.)

1994 ¿Un estado, una lengua? La arganización politica de la diversidad lingüística. Barcelona: Eds, Octaedro.

BERGER, Peter L.

1963 Invitation to Sociology: A Humanistic Perspective. Garden City, New York: Anchor Books.

Berger, Peter L. \& T. LuCKMANN

1983 La construcción social de la realidad. Buenos Aires: Amorrortu eds. (Spanish translation of The Social Construction of Reality, Doubleday \& C. )

BOIX I FUSTER, Emili

1989 Tria i alternança de llengües entre joves de Barcelona: normes d'ús $i$ actituds. Doctoral thesis, Universitat de Barcelona.

1990 "Language choice and language switching among youth people in Barcelona," in: Network on Code-Switching and Language Contact. Papers for the Workshop on Concepts, Methodology, and Data. Strasbourg: European Science Foundation, pp. 209-224.

1993 Triar no és trair. Identitat $i$ llengua en els joves de Barcelona. Barcelona: Eds. 62.

BOURDIEU, Pierre

1980 Le sens pratique. Paris: Les Éditions de Minuit.

1982 Ce que parler veut dire. Paris: Fayard.

BOURHIS, Richard Y.

1984 "Cross-cultural communication in Montreal: Two field studies since Bill ror," International Journal of the Sociology of Language 46, Pp. 33-47.

CAPRA, Fritjof

1984 El Tao de la física. Madrid: Luis Cárcamo, ed. (Spanish translation of The Tao of Physics. Berkeley: Shambhala, 1975).

Cobarrubias, Juan, \& J.A. Fishman (eds.)

1983 Progress in Language Planning. International Perspectives. Berlin: Mouton.

CORBEIL, Jean-Claude

1980 L'aménagement linguistique du Québec. Montréal: Guerin. 
DAvIS, Kingsley

1984 La sociedad humana. Buenos Aires: Eudeba. (Spanish translation of Human Society, The MacMillan C., 1949).

ELIAS, Norbert

1982 Sociología fundamental. Barcelona: Gedisa. (Spanish translation of Was ist Soziologie?, Juventa Verlag München, 1970).

ETXEBARRIA AROSTEgUI, Maitena

1995 El bilingüismo en el Estado español. Bilbao: Ediciones FBV.

G HOWARD, \& R.ST. ClaIR (eds.)

1979 Language and Social Psychology. Oxford: Basil Blackwell.

GUMPERZ, John J.

1985 Discourse Strategies. Cambridge: Cambridge University Press.

HeLleR, Monica

1990 "The politics of code-switching: Processes and Consequences of Ethnic Mobilization," Paper presented at the 3 rd. Workshop of the European Science Foundation Network on Code-Switching.

HAUGEN, Einar

1972 The Ecology of Language. Stanford, Cal.: Stanford University Press.

HINDLEY, Reg

1990 The Death of Irish Language. London: Routledge.

LEWIN, Kurt

1978 La teoría del campo en la ciencia social. Buenos Aires: Paidós. (Spanish translation of Field Theory in Social Science).

MACKEY, William F.

1994 "La ecología de las sociedades plurilingües," in: Bastardas \& Boix,op. cit., pp. 25-54.

MARgAlef, Ramon

1991 Teoría de los sistemas ecológicos. Barcelona: Publicacions de la Universitat de Barcelona.

MEAD, George $\mathrm{H}$.

1934 Mind, Self and Society. Chicago: The University of Chicago Press.

Mirrox, Lesley

1987 Language and Social Networks. Oxford: Basil Blackwell.

SCHUTZ, Alfred, \& T. LUCKMANN

1977 Las estructuras del mundo de la vida. Buenos Aires: Amorrortu. (Spanish translation of The Structures of the Life-World, 1973). 
Siguan, Miquel

1991 España plurilingüe. Madrid: Alianza editorial. (English translation: Multilingual Spain. Lisse: Swets \& Zeitlinger, 1993).

Tuson, Amparo

1985 Language, Community and School in Barcelona. Ph. D. Dissertation, Univ. of California, Berkeley.

1990 "Catalan-Spanish Code-Switching in Interpersonal Communication," Paper for the European Science Foundation Network on Code-Switching.

WOOLARD, K.A.

1983 The Politics of Language and Ethnicity in Barcelona, Spain. Ph.

D. Dissertation, University of California, Berkeley.

1992 Identitat $i$ contacte de llengües a Barcelona. Barcelona: La Magrana. 